\title{
Photogrammetric Survey of Dinosaur Skeletons
}

\author{
Albert Wiedemann ${ }^{1}$, Tim Suthau ${ }^{1} \&$ Jörg Albertz ${ }^{1}$
}

With 9 figures

\begin{abstract}
To derive physiological data of dinosaurs, it is necessary to determine the volume and the surface area of this animals. For this purpose, a detailed survey of reconstructed skeletons is required. The skeletons of three dinosaurs in the Museum für Naturkunde in Berlin and two skeletons in the Muséum d'Histoire Naturelle in Paris have been surveyed using stereo photogrammetry. Two of the Berlin skeletons were also surveyed with the close range laser scanners of the Institut für Navigation of the Universität Stuttgart. Both data acquisition techniques require a geodetic control network as a geometric reference system. The surveying methods used, together with results of mathematical approaches for the determination of the volume and surface of the animals are presented in this paper.
\end{abstract}

Key words: Dinosaur skeletons, survey, photogrammetry, laser scanner.

\section{Zusammenfassung}

Zur Herleitung physiologischer Daten der Dinosaurier ist es erforderlich, zunächst Volumen und Oberfläche ihres Körpers zu bestimmen. Dazu wurde eine detaillierte Vermessung rekonstruierter Skelette durchgeführt. Die Skelette dreier Saurier im Museum für Naturkunde in Berlin und zweier im Muséum d'Histoire Naturelle in Paris wurden stereophotogrammetrisch vermessen. Bei zwei der Berliner Skelette wurden zusätzlich die Laserscanner des Instituts für Navigation der Universität Stuttgart eingesetzt. Beide Datenerfassungstechniken benötigen ein Paßpunktfeld als geometrisches Referenzsystem. Die yerwendeten Vermessungsmethoden, die mathematischen Ansätze für die Berechnung von Volumina und Oberflächen und die Ergebnisse werden in diesem Aufsatz vorgestellt.

Schlüsselwörter: Dinosaurierskelette, Vermessung, Photogrammetrie, Laserscanner.

\section{Objective}

In order to collect data on the paleobiology of dinosaurs, the skeletons must be examined in detail. Considerable physiological data can be acquired, using characteristics of extant animals and methods of comparative physiology based on the body volume and the body surface area. This data can employ mathematical models, if precise data about the skeletons is available.

The Institut für Physiologie der Freien Universität Berlin requested the Fachgebiet für Photogrammetrie und Kartographie der Technischen Universität Berlin to carry out a measurement of the skeleton of Brachiosaurus brancai in the Museum für Naturkunde der HumboldtUniversität $\mathrm{zu}$ Berlin. Photogrammetry is a detailed and precise surveying technique which allows the collection of a large amount of data during a short campaign with no contact to the object.

The skeleton of Brachiosaurus brancai is the largest museum mounted dinosaur skeleton in the world. It was discovered at the beginning of the century in Tendaguru, at that time German East Africa, today Tanzania. Later it was build up in Berlin 1937 (Christian \& Heinrich 1998). The mounted skeleton is a composite. Missing parts are substituted by either elements of skeletons of approximately the same size (e.g., tail) or by plaster reconstructions (e.g., right shoulder blade). Some of the preserved skeletal elements have also been replaced by plaster reconstructions (e.g., cervical and dorsal vertebrae) owing to their fragility (for details see Christian \& Heinrich 1998). The measurement was accomplished 1993/94 with conventional stereo-photogrammetric methods.

\footnotetext{
1 Technische Universität Berlin, Fachgebiet Photogrammetrie und Kartographie, Straße des 17. Juni 135, Sekr. EB9, 10623 Berlin, Germany.

Received March 1999, accepted June 1999
} 
Table 1

Overview on the Surveyed Dinosaur Skeletons

\begin{tabular}{|c|c|c|c|c|c|}
\hline & $\begin{array}{l}\text { Brachiosaurus } \\
\text { brancai }\end{array}$ & $\begin{array}{l}\text { Diplodocus } \\
\text { carnegii } \\
\end{array}$ & $\begin{array}{l}\text { Dicraeosaurus } \\
\text { hansemanni }\end{array}$ & $\begin{array}{l}\text { Iguanodon } \\
\text { bernissartensis }\end{array}$ & $\begin{array}{l}\text { Allosaurus } \\
\text { fragilis }\end{array}$ \\
\hline $\begin{array}{l}\text { Horizontal Length } \\
\text { Height } \\
\text { Control Points }\end{array}$ & $\begin{array}{l}18 \mathrm{~m} \\
12 \mathrm{~m} \\
20\end{array}$ & $\begin{array}{l}23 \mathrm{~m} \\
4 \mathrm{~m} \\
29\end{array}$ & $\begin{array}{l}13 \mathrm{~m} \\
3 \mathrm{~m} \\
17\end{array}$ & $\begin{array}{l}8 \mathrm{~m} \\
4 \mathrm{~m} \\
13\end{array}$ & $\begin{array}{l}8 \mathrm{~m} \\
3 \mathrm{~m} \\
13\end{array}$ \\
\hline $\begin{array}{l}\text { Stereophotogr. } \\
\text { Surveyed Sides } \\
\text { Image Scale } \\
\text { Bases } \\
\text { Polygons } \\
\text { Points on the Object }\end{array}$ & $\begin{array}{l}2 \\
\text { ca. 1:200 } \\
2 \\
572 \\
6518\end{array}$ & $\begin{array}{l}1 \\
\text { ca. } 1: 100 \\
3 \\
993 \\
15059\end{array}$ & $\begin{array}{l}1 \\
\text { ca. } 1: 100 \\
1 \\
322 \\
8367\end{array}$ & $\begin{array}{l}1 \\
\text { ca. } 1: 100 \\
1 \\
298 \\
2817\end{array}$ & $\begin{array}{l}1 \\
\text { ca. } 1: 100 \\
1 \\
280 \\
5190\end{array}$ \\
\hline $\begin{array}{l}\text { Laserscanner } \\
\text { Data Sets } \\
\text { Points }\end{array}$ & $\begin{array}{l}- \\
-\end{array}$ & $\begin{array}{l}21 \\
861021\end{array}$ & $\begin{array}{l}8 \\
589824\end{array}$ & $\begin{array}{l}- \\
-\end{array}$ & - \\
\hline $\begin{array}{l}\text { Results } \\
\text { Segments } \\
\text { Volume } \\
\text { Surface }\end{array}$ & $\begin{array}{l}50 \\
74,4 \mathrm{~m}^{3} \\
140 \mathrm{~m}^{2}\end{array}$ & $\begin{array}{l}75 \\
32,4 \mathrm{~m}^{3} \\
93,4 \mathrm{~m}^{2}\end{array}$ & $\begin{array}{l}50 \\
12,8 \mathrm{~m}^{3} \\
46,4 \mathrm{~m}^{2}\end{array}$ & $\begin{array}{l}64 \\
8,4 \mathrm{~m}^{3} \\
36,1 \mathrm{~m}^{2}\end{array}$ & $\begin{array}{l}55 \\
3,3 \mathrm{~m}^{3} \\
21,2 \mathrm{~m}^{2}\end{array}$ \\
\hline
\end{tabular}

After experience was developed through the measurement of Brachiosaurus the skeletons of two further sauropods were tackled in the Museum für Naturkunde in Berlin in 1996/97: Diplodocus carnegii and Dicraeosaurus hansemanni. Dicraeosaurus also originates from Tendaguru. The head is also a cast. Diplodocus is represented by a complete cast of the skeleton from the USA. As its original has been stored in dark rock, even the copy was accordingly dark, while both other Dinosaur skeletons are clearly brighter. In the case of this two skeletons in addition to the photogrammetric approach, the two laser scanners of the Institut für Navigation of the Universität Stuttgart were used (Wiedemann \& Wehr 1997).

In spring 1998 two further dinosaur skeletons were surveyed in the Muséum d'Histoire Naturelle in Paris, France: Iguanodon bernissartensis and Allosaurus fragilis. Here only stereo photogrammetry was used, based on the experiences of the former campaigns. In the Table 1 the most important data of the dinosaur skeletons, the photographs and the results are summarized.

\section{Geodetic measurements}

Both for photogrammetric and laser scanner work a network of geodetic surveyed control points is necessary. About 10-20 control points have been signalized at and around each skeleton using polystyrene balls of about $20 \mathrm{~mm}$ diameter. The survey has been done using a Sokkia total station and an automatic data registration and data flow to the network adjustment software.

First a polygon was measured to determine the location of the instrument stations by measuring angles and distances with the theodolite system and the electronic distance measurement system in the total station. Then each control point has to be measured from at least two different stations to allow the calculation of the points by ray intersection. These points were measured sides with an accuracy of $\pm 10-20 \mathrm{~mm}$. The geodetic measurement of the required control points lasts a few hours, depending on the circumstances. Measurements in a cramped environment are problematic, because other objects may obstruct important views.

Further tie points in the form of glued on paper marks of about $5 \mathrm{~mm}$ in diameter were attached to the skeletons and the background. These were not geodetic measured, but can be clearly identified and precisely measured in the metric images.

\section{Photogrammetric measurements}

The dinosaur skeletons consist of many individual bones, whose position and form must be 


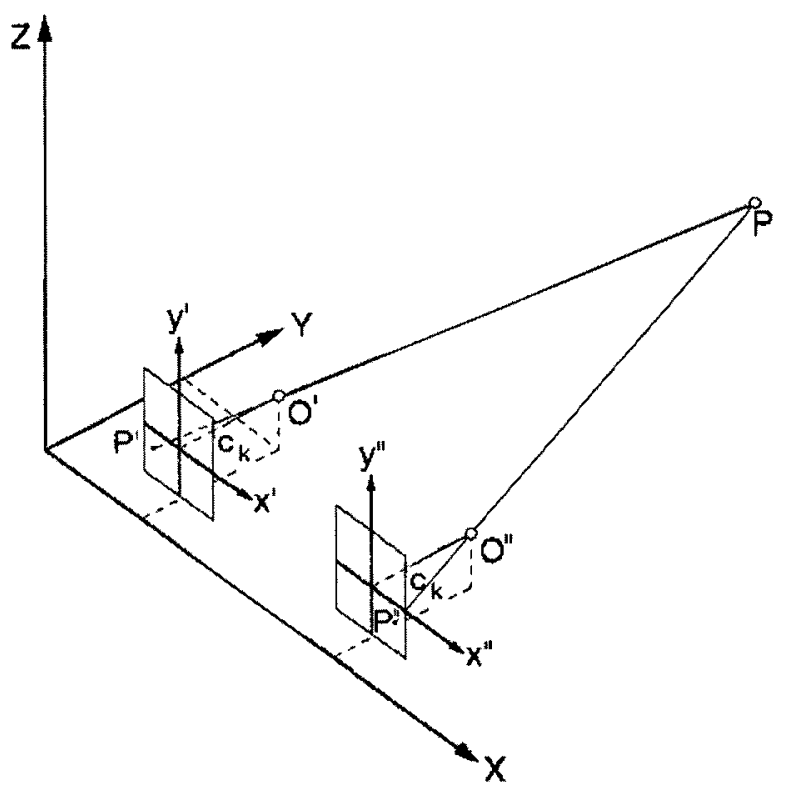

Fig. 1. Principle of stereophotogrammetry

determined. Because of the absence of clearly identifiable points only a stereo photogrammetric measurement was applicable. The stereo photogrammetric approach is based on the use of two images, acquired from two different locations. The line between these two projection centers $\left(\mathrm{O}^{\prime}, \mathrm{O}^{\prime \prime}\right)$ is called base. The viewing directions should be parallel and perpendicular to the base (Fig. 1). This image arrangement is comparable to the arrangement of our eyes. If each image is arranged to an other eye, we are able to see a $3 \mathrm{D}$ model. This is used in an analytical stereo photogrammetric instrument, such as the Kern DSR11 at the Technical University of Berlin (Fig. 2). In such an instrument a 3D measurement mark can be moved in three dimensions and the movement can be stored to build up a 3D CAD wire model.

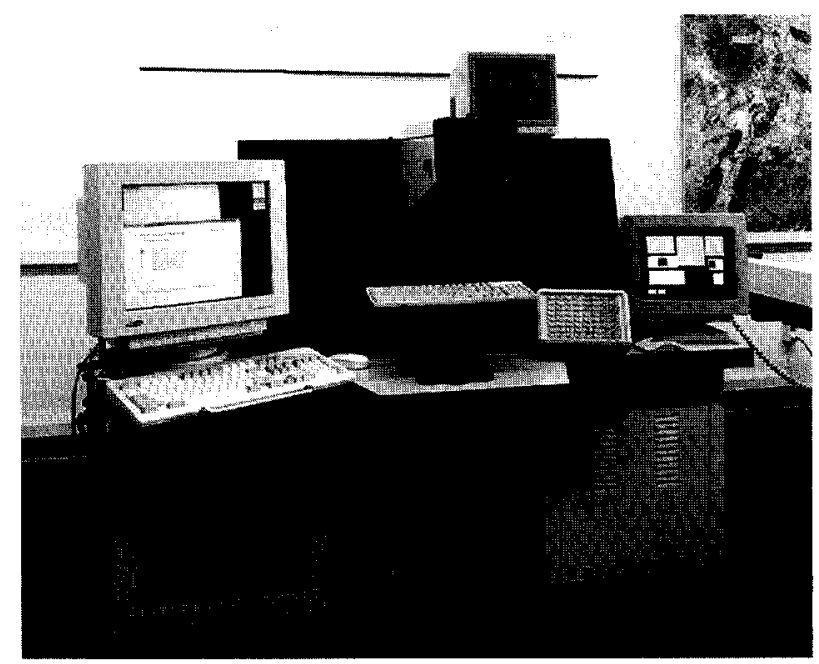

Fig. 2. Analytical Instrument Kern DSR11

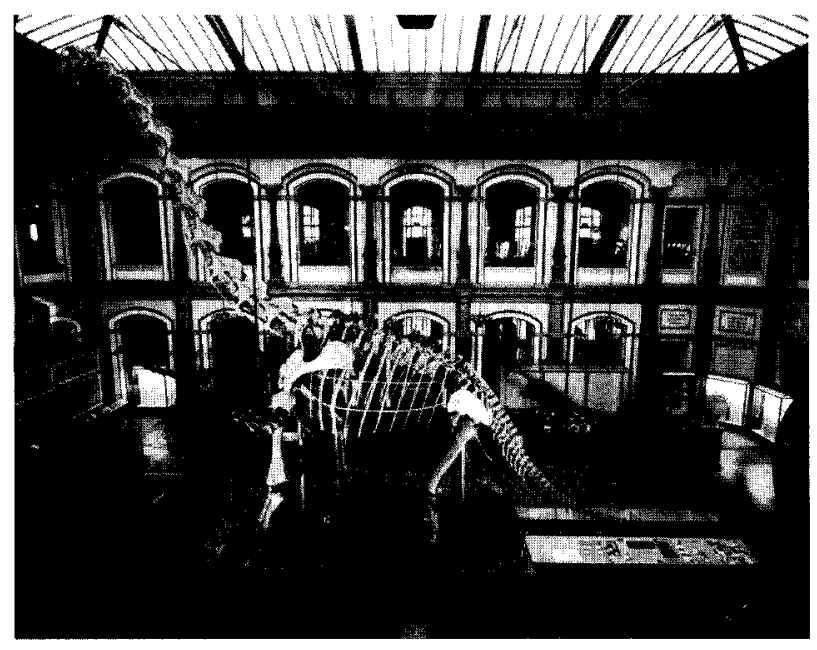

Fig. 3. Metric image of Brachiosaurus brancai

The Brachiosaurus skeleton is located in the center of the main hall of the Museum für Naturkunde and was imaged from both sides. The photographs were acquired from the gallery with the terrestrial metric camera Zeiss TMK 6 (Fig. 3). The selected base-to-distance relationship of approx. 1:1 led to very large parallaxes, which proved problematic during the restitution. The stereoscopic view was very difficult to interpret, since the skeleton has no closed surface but intersecting rays had to be evaluated.

The fusion of the two models permitted the development of one CAD wire model (Fig. 4), consisting of the outlines of the edges of the bones in lateral view. For this reason, the evidence of the bone outlines in other views is limited. A parallel projection of the data set into one vertical plane along the longitudinal axis of the skeleton was used to form a diagram of the
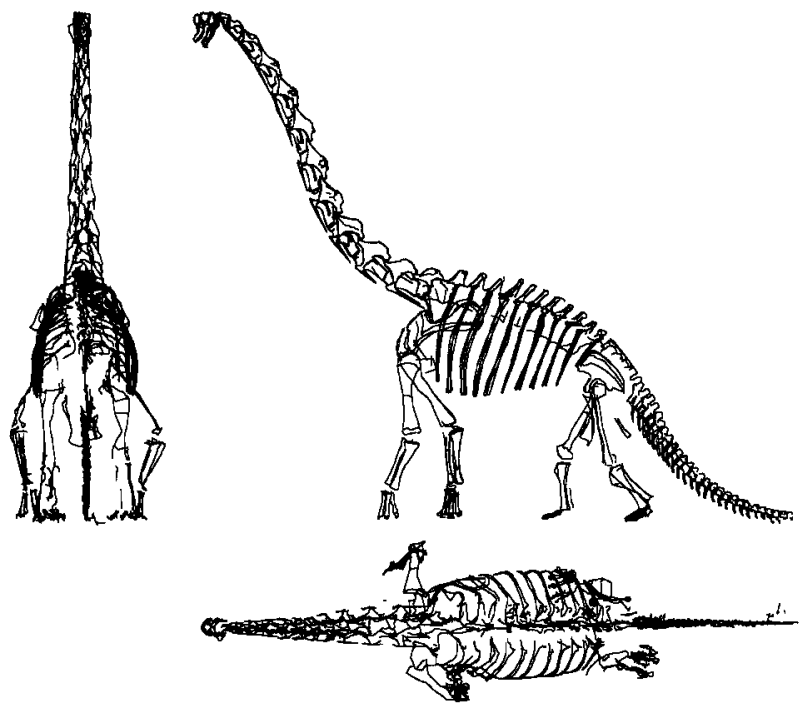

Fig. 4. Restitution result of Brachiosaurus brancai in three views 


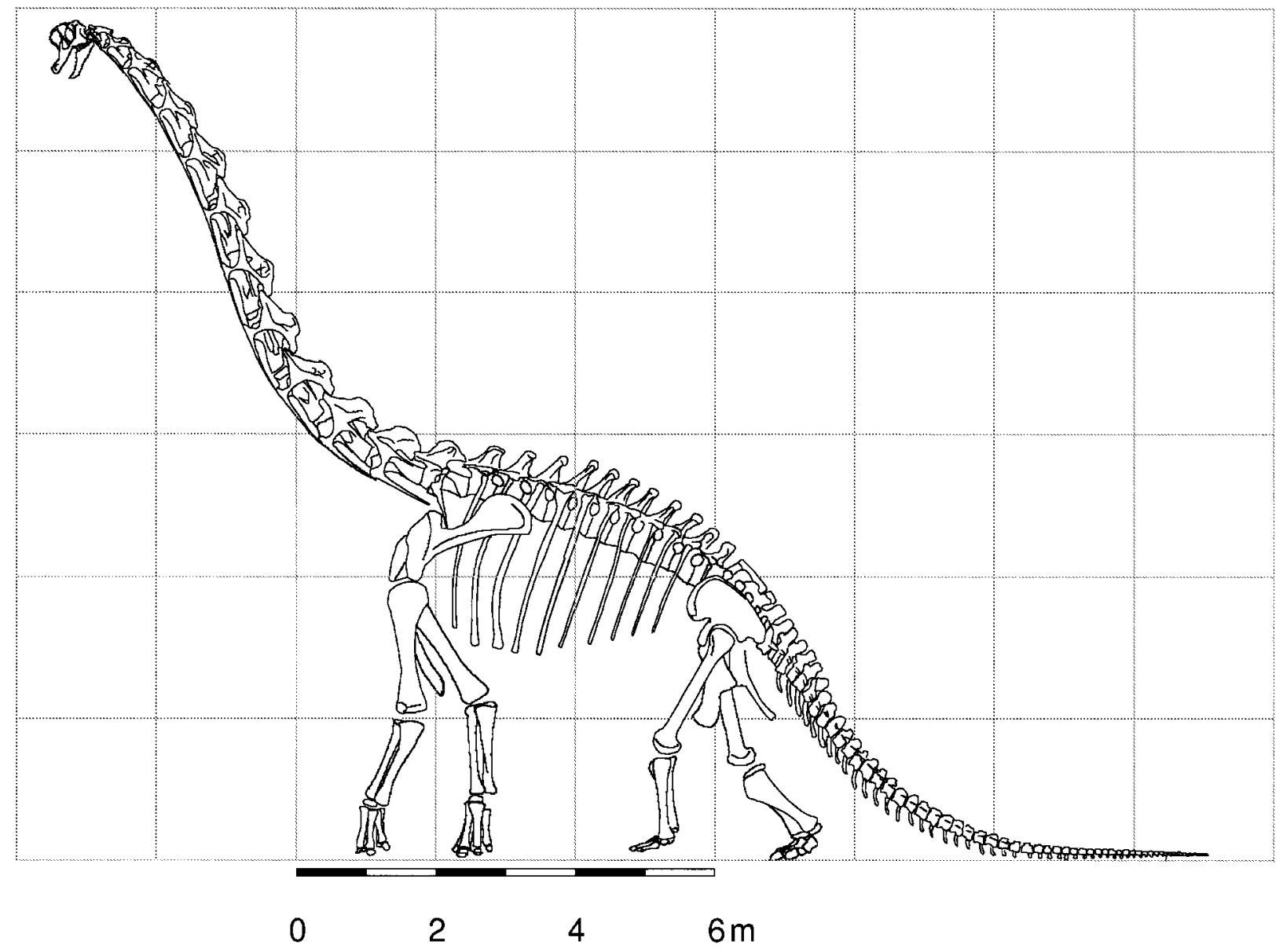

Fig. 5. Result of the stereophotogrammetric restitution

skeleton (Fig. 5). From this physiologists were able to derive considerable data (Gunga et al 1995).

Due to the length of the specimen we had to acquire Diplodocus carnegii in three photogrammetric models. Dicraeosaurus hansemanni was acquired in only one photogrammetric model, ignoring the last 4 meters of the tail. Both skeletons can be accessed only from one side. During this second photograph campaign the background of glass proved as disturbing for optimal lighting conditions for the photogrammetric picture recording. Reflections made a balanced illumination more difficult. In particular on the darker Diplodocus skeleton it was difficult to detect the structures on the bones on the photographic material. Nevertheless more details could be captured due to the larger image scale and the more suitable base-to-distance relationship compared to the measurements at Brachiosaurus.

Based on the experiences in Berlin some accelerated and improved techniques have been used during the measurement campaign in Paris. The windows and showcases in the Muséum d'Histoire Naturelle around the skeletons have been covered using paper and blankets. A prob- lem was the build up of the skeletons, which are very close to other objects. For backup reasons we acquired a few stereo pairs, but only one pair per object was required to survey most of the skeletons.

\section{Laser scanner}

To support the photogrammetric data acquisition and to evaluate new technologies the two smaller dinosaur skeletons in Berlin were also surveyed with the two laser scanners (Fig. 6) of the Institut für Navigation der Universität Stuttgart (INS). With this system a laser beam is directed over a room segment by two rotating mirrors to scan the surfaces. Apart from the intensity of the reflected signal the phase of two measurement signals is also recorded. From these phase measurements the distance between the system and the reflecting surface can be derived. The two skew angles and the object distance define a set of polar coordinates for the object points. The intensity of the reflected signal supplies additional information. Distances and intensity are stored in raster files, the vertical skew angle de- 


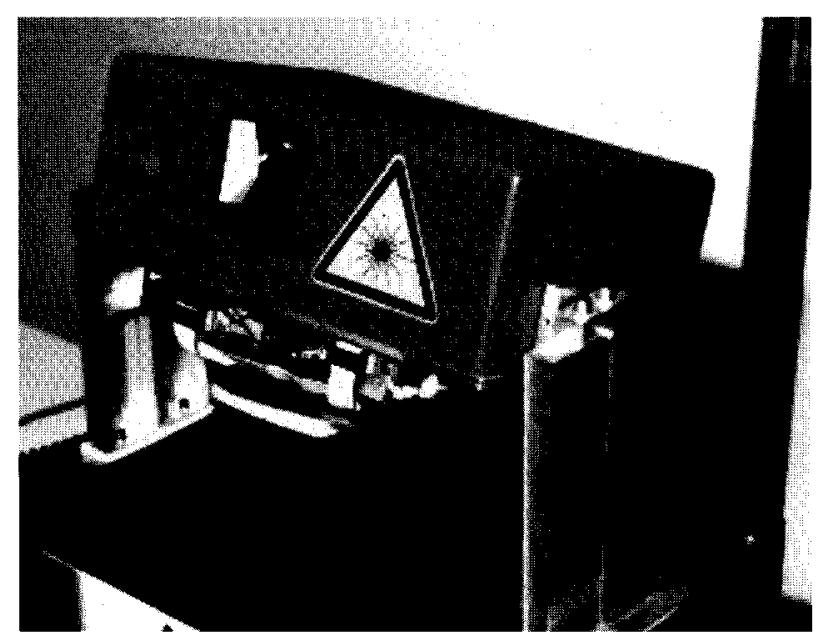

Fig. 6. Laser scanner

fines the lines and the horizontal skew angles represent the columns. From these polar coordinates cartesian coordinates in a local system can be computed with simple formulas (Wehr 1997).

The survey of the skeletons took place in segments of $400 \times 400$ points with a field of view of approximately $30^{\circ} \times 30^{\circ}$ in azimuth and elevation. The range was limited to a few meters, depending on the reflectance of the objects surface. The control points signals could be identified in the distance image and in the intensity image, signalized tie points only in the intensity image. With the help of the geodetic control points the individual spatial point clouds were transformed into the common coordinate system of the geodetic network.
As with the photogrammetric image acquisition, the glass background proved problematic. The laser signal was reflected by the glass, or bent or passed through and reflected from the neighbor room. Apart from other interferences this led to measurements greater than $10 \mathrm{~m}$, which resulted in ambiguities. In order to prevent this, we covered the glass plates with paper or linen sheets.

Whereas the data acquisition at Dicraeosaurus required eight data sets, 21 data sets were necessary to scan Diplodocus. After the measurement, the data sets were filtered and merged to one data set for each of the two skeletons. From this data sets, the depth map and parallel projections can be deduced (Fig. 7). The gap in the tail of Dicraeosaurus results from an area occluded by a showcase.

The intensity of the reflected signal is a function of the reflection characteristics of the objects surface, the wavelength of the carrier wave and the exposition of the surface in relation to incident light. For example in the darker head of Dicraeosaurus (Fig. 7), the gypsum reflects the carrier wave of the measuring signal less effective than the petrified bones of the neck. Dark surfaces reflect more poorly than light surfaces. The combination of these two reflection characteristics caused problems with Diplodocus. A sufficient signal could only be achieved using a shorter distance, so that more data sets were necessary than planned. Owing to the high albedo of the dust on the skeleton it could nevertheless

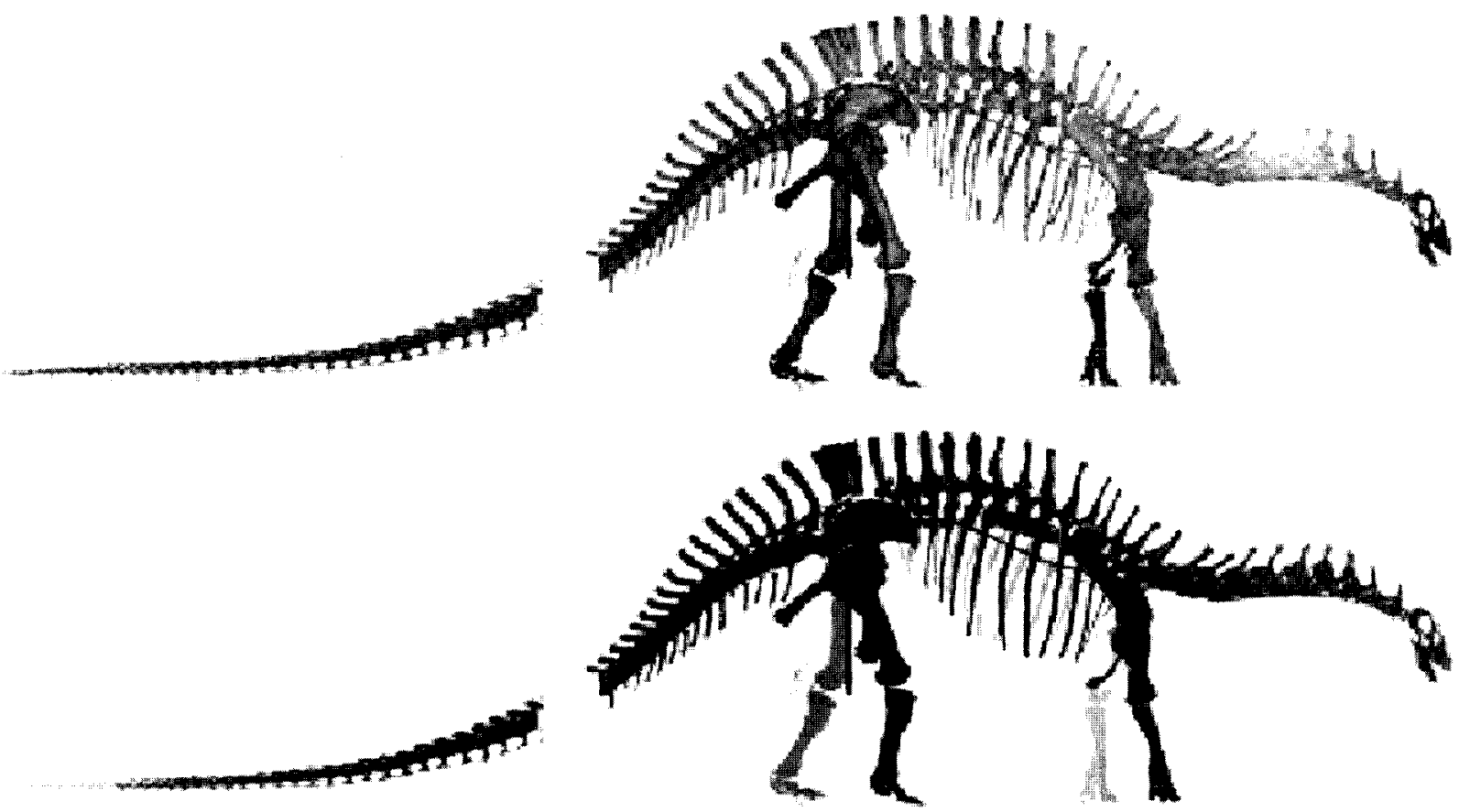

Fig. 7. Data of Dicraeosaurus composed from 8 data sets showing intensity (upper) and distance (lower) images 


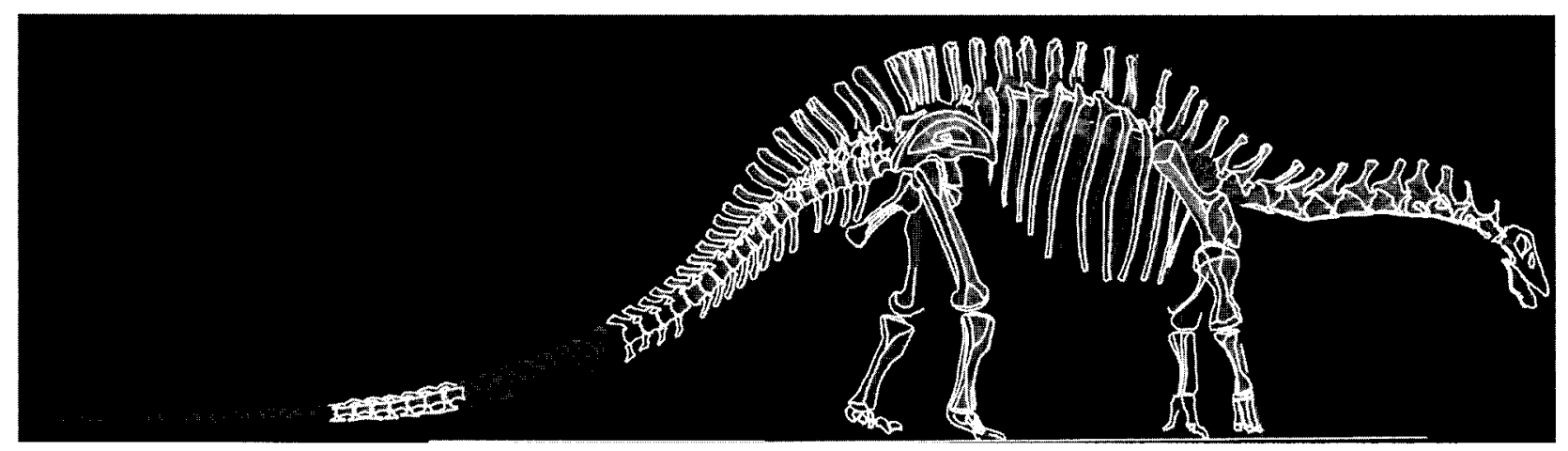

Fig. 8. Stereophotogrammetric restitution superimposed on the intensity image

be measured. Figure 8 shows the superimposition of a stereophotogrammetric restitution result upon the intensity image of the laser scanner.

\section{Results and interpretation}

The results of all stereophotogrammetric restitutions are shown in Fig. 9 at the same scale to give an indication of the relative size of the different skeletons. The next step was to deduce the body forms of the dinosaurs. For this purpose a flesh layer, reconstructed by the physiologists was added to the wire model of the skeleton, and three-dimensional geometric primitives have been selected to adjust the form of the 3D model. Most of them were truncated cones and spherical caps. Thus a barrel form resulted for example for the torax. With the help of these primitives the volume and the surface of the dinosaur were computed.

New calculations based on numerical integration of the cross section area through the CAD model of Brachiosaurus brancai resulted in an overall volume estimation of $15-20 \mathrm{~m}^{3}$ less than in the recent calculations.

The results serve palaeo-physiologists as initial values for the determination of a multiplicity of further physiological data. A lot of them can be found in the paper of Gunga et al. (1999) in the same volume.

The evaluation of the results must consider the following possible sources of error:
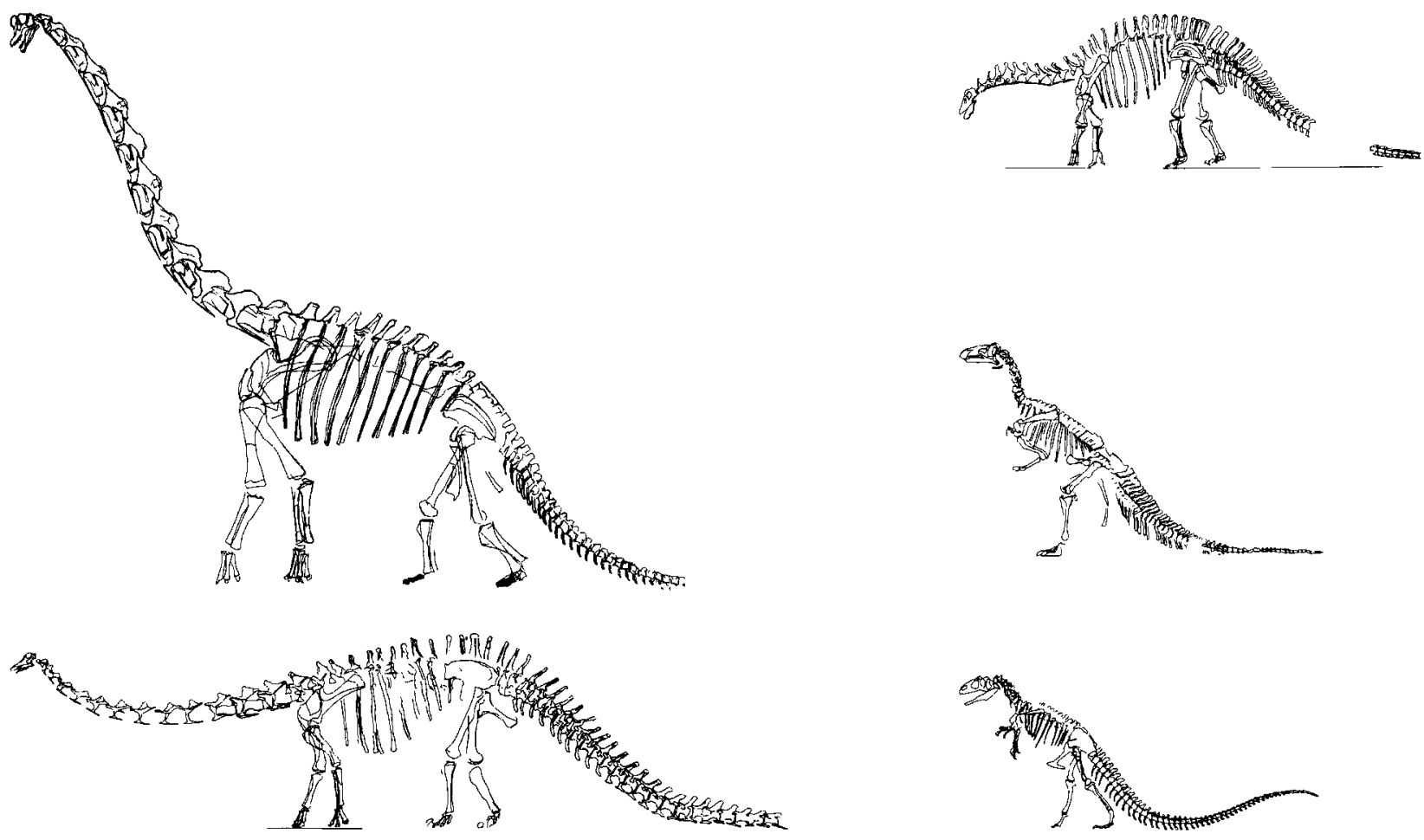

Fig. 9. Comparison between Brachiosaurus (upper left), Diplodocus (lower left), Dicraeosaurus (upper right), Iguanodon (middle right) and Allosaurus (lower right) showing their skeletons in the same scale 
- Incorrect construction of the skeleton: Such error influences can be avoided only by a careful preparation of the skeleton and a scientifically based reconstruction. The structure of the skeletons in Berlin is considered as scientifically based.

- Inaccurate measurement: The adjustment of the geodetic measurement resulted in mean errors of 10-20 mm. With an image scale of approx. $1: 100$ to $1: 200$ the expected photogrammetric inaccuracies are within the range of a few millimeters. These are usually more exact than the point definition on the skeleton.

- Estimation of the flesh layer: The thickness of the flesh layer varies in the food supply and must therefore have varied considerably. While the influence of this on the surface can be neglected, it is substantial for the computation of volumes. In particular in the lower belly area, where no bones are present the shape is uncertain.

- The mathematical model used for the calculation of surface and volume: The use of a circular cross sections appears somewhat questionable in the region of the thorax. In particular if one views the skeleton of Brachiosaurus from above and from the side, one recognizes that the trunk is clearly higher than broad (Fig. 4). This is problematic particularly because of the enormous portion that the trunk contributes to the total volume of the dinosaurs.

\section{Conclusions}

The photogrammetric work consists of two main phases - first preparation, measurement of control information and image acquisition. This has to be done during the campaign and lasts about one or two days per skeleton. This is fast in consideration to the enormous amount of data acquired. The second phase is much more time consuming and consists of the adjustment of the geodetic measurements, the development and orientation of the images and the tedious restitution work with the stereo photogrammetric instrument. The required time for this work lasts weeks, but can be carried out independently from the campaign at any time at home.

It has been shown already that the results of the work with the laser scanner were more quickly available than the results of the photogrammetric evaluation. However the techniques must be further improved for the elimination of incorrect measurements from the point clouds of the laser scanners. In particular at the edges of the bones a wrong distance was computed as weighted mean value of foreground (bone) and background. The main drawback of the laser scanner system is the limited range, which required the data acquisition in a lot of individual data sets, what is very time consuming. This will change in the near future with a further development of the system.

\section{Acknowledgements}

The work of the project "Dinosaurier Lagerstätte Tendagu ru" is supported by the Deutsche Forschungs-Gemeinschaft (DFG).

We thank PD Dr. med. Dipl.-Geol. Hanns-Christian Gunga and Professor Dr. med. Karl A. Kirsch, from the Institut für Physiologie der Freien Universität Berlin, for the initiation of this project and the support of our work. Further thanks to the staff of the Museum für Naturkunde der Humboldt-Universität zu Berlin, especially Dr. Wolf-Dieter Heinrich and Prof. Hans-Peter Schultze, who gave us access to the skeletons and supported us in every possible manner. Further we want to thank the following persons at the Fachgebiet Photogrammetrie und Kartographie der Technischen Univerisität Berlin: Klaus Witt for the qualified support with all photographic works and students Wolfram Lisowski and Sascha Mokry for the tedious stereo-evaluations and post processing. Many thanks to Dr.-Ing. Aloys Wehr and Dipl.Ing. (FH) Martin Thomas of the Institut für Navigation der Universität Stuttgart for the data acquisition and preparation of the laser scanner data.

\section{References}

Christian, A. \& Heinrich, W.-D. 1998. The neck posture of Brachiosaurus brancai. - Mitteilungen aus dem Museum für Naturkunde in Berlin, Geowissenschaftliche Reihe 1: 73-80.

Gunga, H.-Chr., Kirsch, K. A., Baartz, F., Röcker, L., Heinrich, W.-D., Lisowski, W., Wiedemann, A. \& Albertz, J. 1995. New Data on the Dimensions of Brachiosaurus brancai and their Physiological Implications. - Naturwissenschaften 82: 190-192.

Gunga, H.-Chr., Kirsch, K. A., Rittweger, J., Clarke, A., Albertz, J., Wiedemann, A., Mokry, S., Suthau, T., Wehr, A., Heinrich, W.-D. \& Schultze, H.-P. 1999. Body size and body volume distribution in two sauropods from the Upper Jurassic of Tendaguru/Tanzania/East Africa. - Mitteilungen aus dem Museum für Naturkunde in Berlin, Geowissenschaftliche Reihe 2: 91-102.

Wehr, A. 1997. Abbildende Laserscanner - Anwendungen in Bauaufnahme und Denkmalpflege. In Albertz, J. \& Wiedemann, A. (eds.): Architekturphotogrammetrie gestern - heute - morgen. - Technische Universität Berlin 1997: $114-127$

Wiedemann, A. \& Wehr, A. 1998. Vermessung von Dinosaurierskeletten mit Stereophotogrammetrie und Laserscanner. In List, F. K. (ed.): Photogrammetrie im Wandel, Lehre - Forschung - Anwendung. - Proceedings of the Annual Meeting of the Deutsche Gesellschaft für Photogrammetrie und Fernerkundung (DGPF), 1997 in Frankfurt/Main, Band 6: 301-308, Berlin. 